\title{
Histopathological changes in the liver and thyroid of mice (Mus musculus) caused by the acaricides: fipronil and thymol
}

\author{
Eric Leonardo Rodrigues da Cunha ${ }^{1 \dagger}$, Renata da Silva Matos ${ }^{1 \dagger}$, Natalia Rubio Claret Pereira ${ }^{1 \dagger}$, Patrícia Rosa de Oliveira ${ }^{1 \dagger}$, Erik Daemon $^{2 \dagger}$ \\ and Maria Izabel Camargo-Mathias ${ }^{1 *}$
}

${ }^{*}$ Correspondence: micm@rc.unesp.com

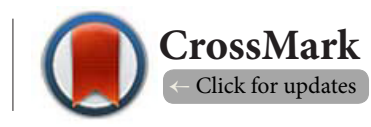

†These authors contributed equally to this work.

'Departamento de Biologia, Instituto de Biociências, Universidade Estadual Paulista "Júlio de Mesquita Filho" - UNESP, Rio Claro, SP, Brazil.

${ }^{2}$ Departamento de Biologia, Universidade Federal de Juiz de Fora, Juiz de Fora, MG, Brasil.

\begin{abstract}
The control of tick Rhipicephalus (Boophilus) microplus, that has the cattle as preferential host, has been performed using products based on different chemical substances. However, the indiscriminate use of these products has caused the selection of resistant populations and damages to the environment, contaminating the soil and water. Tickcides, like fipronil (synthetic chemical) and thymol (natural chemical), are applied on cattle through aspersion, causing the death of the ectoparasites. Nevertheless, the effects of these products on nontarget organisms have not been thoroughly investigated. Thus, this study evaluated the morphology of the liver and thyroid of female Mus musculus mice, divided into 5 treatment groups/5 individuals each, exposed to fipronil $(2 \%)$ and thymol $(2 \mathrm{mg} / \mathrm{mL})$ through aspersion baths. After exposure, the mice were euthanized with anaesthetic overdose and dissected for organ removal. The results showed that both fipronil and thymol caused morphological alterations in the organs: cytoplasmic vacuolation, cell death characteristics in hepatocyte nuclei and structural disorganization of the thyroid gland. Along with body weight measurement, the results suggest that the morphological alterations would be a systemic response of the organism to the toxic action of these products, regardless their origin (synthetic of natural).
\end{abstract}

Keywords: Morphology, tickcide, tissue damage, acute toxicity, Mus musculus

\section{Introduction}

Dairy and beef cattle breeds are economically important in many Brazilian regions. Rhipicephalus (Boophilus) microplus, also known as cattle tick, is one of the most relevant ectoparasites, which causes direct and indirect damages to the hosts [1].

The most efficient and widely used chemical control against these ectoparasites is performed through tickcide baths; i.e., the aspersion of the diluted product [2]. However, the use of such products causes environmental problems, contaminating the soil and rivers with residues and affecting nontarget organisms coexisting with the cattle [3].

The problem when aspersions are performed on pastures is the bioaccumulation and the persistent contamination of the area, introducing contaminants in the animal food chain, including the human being, once the latter consume milk and meat containing residues of toxic substances from the chemical products used to control the pests. Such residues cause cell and tissue damages, which are, in many cases, irreversible. Additionally, the emergence and selection of extremely resistant tick strains has been observed $[4,5]$.

Synthetic products currently in use to control ticks are fipronil [6], permethrin [7], fluazuron [8], dinotefuran [9] and deltamethrin [10] Among them, fipronil, an acaricide that belongs to the chemical group phenylpyrazole, acts specifically on the central nervous system (CNS) of the invertebrate [11]. This synthetic chemical has great efficiency in controlling resistant/tolerant pest, which justifies its widespread use in several countries [6], although it is highly toxic for some animal species [12]. 
However, little is known about the effects of this chemical on the cells and tissues of vertebrate in general. New alternatives to control pest ticks have been sought, including the use of plant-derived products [13], such as thymol [14], carvacrol [15], the neem seed oil (Azadirachta indica) [16], the andiroba oil (Carapa guianensis) [17] and castor oil (ricinoleic acid esters from Ricinus communis) [18].

Among the chemicals extracted from plants, thymol is a volatile monoterpene present in the essential oils of Apiaceae, Lamiaceae and Verbenaceae plants and has acaricide action when applied to different stages and species of ticks [19]. Thymol chemical structure contains a hydroxyl group that enables permeability to the cell membrane and causes damages to the cells and tissues, killing ticks [20]. Also, thymol have been proven to be efficient and less harmful to the environment and nontarget organisms [19].

It is important to emphasize the importance of further studies to investigate the action of these chemical products (fipronil and thymol) on the morphophysiology of the organs of nontarget organisms.

The liver, located in the abdominal cavity, just below the diaphragm, is a toxicity indicator in the mammals. This organ is in a strategic position to metabolize, accumulate, and neutralize the substances absorbed by the intestine. The hepatocyte (hepatic unit), is polyhedral in shape, has one or two central round-shaped nuclei with one or two evident nucleoli, and has the function to accumulate glucose, mainly in the form of glycogen [21].

In mammals, the thyroid is an endocrine gland of critical importance for the regulation of the metabolism in general. It is located at the anterior cervical region of the neck and synthetizes the hormones triiodothyronine (T3), thyroxine (T4). The thyroid is constituted of spherical units named thyroid follicles, surrounded by a simple cuboidal epithelium filled with colloid (prehormone). The thyroid follicles present extensive blood and lymphatic vascular supply, the former responsible for collecting the hormones produced by the gland. This organ is an excellent bioindicator in toxicology studies, once it is very sensitive to toxic exposure, even in minimum dosages $[22,23]$.

In this sense, histology has been frequently used to evaluate the toxicity of a chemical substance, mainly in organs considered as vital. Rodents have been increasingly used in this kind of study, once they are prospective regarding the action of chemicals in humans. Furthermore, the organs that are considered vital are good histological biomarkers in toxicity assays [24].

Thus, the present study had the objective to study, comparatively, the morphohistological alterations on the liver and thyroid of female Mus musculus mice when exposed (via aspersion, simulating field application) to the acaricides fipronil and thymol. The evaluation was performed through the application of histopathological techniques on the liver, and thyroid of the females to be exposed to the acaricides.
Another indicator of possible toxic effects, body mass loss, was also analyzed after the exposure.

\section{Methods}

Twenty-five healthy female Swiss mice (Mus musculus) were used, weighing approximately $20 \mathrm{~g}$, and aged between 5 and 6 weeks. The mice, provided by the Animal Facility from UNESP Botucatu, SP, Brasil, were divided into five groups (five animals each), housed in polypropylene cages $(30 \times 20 \times 13 \mathrm{~cm})$, and maintained under controlled conditions $\left(22^{\circ} \mathrm{C} \pm 2^{\circ}, 50 \%\right.$ humidity, appropriate ventilation, exhaustion and $12 \mathrm{~h}$ photoperiod), receiving commercial food and filtered water ad libitum.

For better identification, the mice had their tails marked using nontoxic markers. Prior to the experimental procedure, the animals were kept for 14 days in the Animal Facilities of the Bioscience Institute, UNESP, campus Rio Claro for adaptation. The present study was approved by the Animal Research Ethical Committee of the Bioscience Institute, UNESP/Rio Claro/ SP/Brazil, protocol number 4243, CEUA 14/2015.

\section{Chemical products used}

Fipronil, at the concentration of $2 \%$, diluted in propylene glycol $10 \%$ and deionized water, using the product provided by UPVET ${ }^{\circledast}$ (veterinary compounding pharmacy registered in the Ministry of Agriculture, Livestock and Supply, according to Decree 5053 of April/22, 2004).

Thymol, obtained from Sigma-Aldrich with 99\% purity, in formulations, at the concentration of $2 \%$, via dilution in hydroethanolic solution at $30 \%(\mathrm{v} / \mathrm{V})$, based on the lethal concentration for R. (Boophilus) microplus [19].

\section{Exposure bioassay}

The animals were divided into five groups:

- Group I: Control I. Sprinkled with distilled water, simulating a tickcide bath.

- Group II: Control II. Sprinkled with propylene glycol, fipronil diluent, at the concentration of $10 \%$ in deionized water.

- Group III: Control III. Sprinkled with hydroethanolic solution at 30\% $(v / v)$ (ethanol 30\%), thymol diluent.

- Group IV: Sprinkled with fipronil at 2\%, diluted in propylene glycol $10 \%$ in deionized water.

- Group V: Sprinkled with thymol in the concentration of $2 \mathrm{mg} / \mathrm{mL}$, diluted in hydroethanolic solution $30 \%(\mathrm{v} / \mathrm{v})$ (ethanol 30\%).

The exposures were performed in three consecutive days, at 24-hour intervals, once the tickcide baths must be consecutively performed within the maximum of three days [25]. The aspersion was performed using sterilized spray bottles and the chemicals were applied until the animal was thoroughly wet (approximate volume of $18 \mathrm{~mL}$ ), simulating field procedure [25].

\section{Obtaining the body mass}

All the animals were individually weighed using scale Marte, 
model LC1, at the Animal Facility of the Biology Department, Bioscience Institute, UNESP, Rio Claro, SP, Brazil, every other day, until euthanasia. The weights were recorded and statistically analyzed through ANOVA ( $p<0.05)$, software GraphPad Prism 6.0. The same software was used to elaborate the body mass graphs before and after the animals were exposed to the acaricide.

\section{Histology}

After 14 days, the animals were anesthetized with ketamine hydrochloride ( $80 \mathrm{mg} / \mathrm{kg} \mathrm{BM} / \mathrm{IP})$ and xylazine hydrochloride (20 $\mathrm{mg} / \mathrm{kg} \mathrm{BM} / \mathrm{IP}$ ) for the removal of the liver and thyroid, which were fragmented and immediately fixed in paraformaldehyde $4 \%$. The material was transferred to phosphate buffered saline for 24 hours and dehydrated in crescent ethanol series $(70$ $80,90,95 \%)$ at 1-hour intervals, and finally embedded and included in Leica resin. The material was sectioned at $3 \mu \mathrm{m}$ thickness in microtome Leica RM 2145 and stained according to Harris hematoxylin-eosin protocol (HE) [21].

The slides were analysed under bright-field microscopy and photographed using photomicroscope MOTIC BA 300. The figures were elaborated using software CorelDRAW X8 and CoreIPHOTO-PAINT X8.

For the quantification of Kupffer cells, a 100 point-test grid was superimposed to the images of the histological sections obtained from all the animals. Ten random fields of $400 x$ magnification were randomly counted for each sample of each animal $[26,27]$.

\section{Results}

Body mass alteration after the bioassay with aspersions of fipronil $2 \%$ and thymol $2 \mathrm{mg} / \mathrm{mL}$

All the mice used in the bioassays were daily and individual weighed, before and after exposure to the products. This procedure was performed until the euthanasia. The first exposure was made on the 42th day after the mice's birth and the euthanasia on the 56th.

Table 1 shows the values corresponding to weight gain in the individuals weighed and the means expressed after statistical analysis ( $p<0.05$ ANOVA). In control group I (distilled water), the animals' body mass show linear increase, expected for healthy mice, without diet restrictions or suffering intoxication effects. In control group II (propyleneglycol 10\%, fipronil diluent), the animals lost weight between the 50th and 52nd day. The animals belonging to control group III (ethanol $30 \%$, thymol diluent) had their weights increased, similarly to the ones from control group I (distilled water).

The mice exposed to fipronil $2 \%$ lost weight after the first exposure and between the 50th and 52nd days of life, as in the control group II (propylene glycol 10\%, fipronil diluent) (Table 1). The animals belonging to group $\mathrm{V}$, exposed to thymol, presented the highest values of average weight gain after the first day of the bioassay (first exposure to the tickcide) (Table 1).

\section{Histology \\ Liver}

In this study, it was observed that hepatic tissue of the control group I mice (exposed to distilled water) was shown to be intact with hepatocytes organized in cords (Figure 1C), arranged radially. The hepatocytes exhibited preserved morphology (Figure 1C), results like those described in the relevant literature. Kupffer cells were evidenced by their elongated nuclei and located between the hepatic cords (Figure 1C). Similarly, in the control group II (exposed to propylene glycol $10 \%$ - fipronil diluent) (Figures 1D and 1E) and III (exposed to ethanol 30\% - thymol solvent) (Figures $1 \mathbf{F}$ and $\mathbf{1 G}$ ), it was also observed that the liver tissue was intact.

In the mice from the treatment group IV (exposed to 2\% fipronil - synthetic chemical), unlike that observed in those controls (I, II and III), we observed the presence of morphological alterations, such as: 1) hepatocytes with cytoplasmic vacuolization (Figure 1K);2) areas of hepatocytes with strong cytoplasmic granulation, probably of glycogen origin (Figures $1 \mathrm{~J}$ and $1 \mathrm{~K}$ ); 3) hepatocytes' nuclei with characteristics of cell death processes, that is, with marginalized chromatin (Figure 11); 4) hypertrophy (Figure 11), presence of many nucleoli (Figure 1I) and irregular nuclei (Figure 1K). Extracytoplasmic vacuolization (with empty spaces) was also observed between hepatocytes, which gave the organ a spongy appearance.

In the mice exposed to thymol $2 \%$ (group V) morphological

Table 1. Mice weight gain (g) every two days after the first exposure.

\begin{tabular}{lllllll}
\hline & Groups & $\mathbf{I}(\mathbf{n}=\mathbf{5})$ & $\mathbf{I I}(\mathbf{n}=\mathbf{5})$ & $\mathbf{I I I}(\mathbf{n}=\mathbf{5})$ & $\mathbf{I V}(\mathbf{n}=\mathbf{5})$ & $\mathbf{V}(\mathbf{n}=\mathbf{4})$ \\
\hline \multirow{4}{*}{ Days } & $42-44$ & $1,0 \pm 0,4$ & $1,2 \pm 0,32$ & $0,6 \pm 0,48$ & $0,8 \pm 0,96$ & $1,0 \pm 0,75$ \\
& $44-46$ & $1,0 \pm 0,0$ & $1,2 \pm 0,48$ & $1,2 \pm 0,32$ & $0,8 \pm 0,64$ & $1,4 \pm 0,55$ \\
& $46-48$ & $1,0 \pm 0,4$ & $1,8 \pm 0,84$ & $0,4 \pm 0,68$ & $1,2 \pm 0,64$ & $0,5 \pm 0,5$ \\
& $48-50$ & $0,4 \pm 0,64$ & $0,4 \pm 0,64$ & $1,4 \pm 0,6$ & $0,4 \pm 0,72$ & $1,5 \pm 0,5$ \\
& $50-52$ & $0,4 \pm 0,48$ & $-0,8 \pm 0,96^{\mathrm{a}}$ & $0,0 \pm 1,4$ & $-0,8 \pm 1,36^{\mathrm{b}}$ & $0,5 \pm 0,25$ \\
& $52-54$ & $1,0 \pm 0,0$ & $1,0 \pm 0,0$ & $0,8 \pm 0,32$ & $0,8 \pm 0,72$ & $1,75 \pm 0,375^{\mathrm{c}}$ \\
& $54-56$ & $0,6 \pm 0,48$ & $0,6 \pm 0,48$ & $1,0 \pm 0,0$ & $0,0 \pm 0,8$ & $1,0 \pm 0,5$ \\
\hline
\end{tabular}

Data expressed with mean \pm SEM (standard error of the mean), $\mathrm{n}=$ animals per group. Values followed by letter are significantly different ( $p<0.05$ ANOVA); I: distilled water (control I); II: propylene glycol 10\% (control II); III: ethanol 30\% (control III); IV: fipronil $2 \%$; V: thymol $2 \mathrm{mg} / \mathrm{mL}$. 


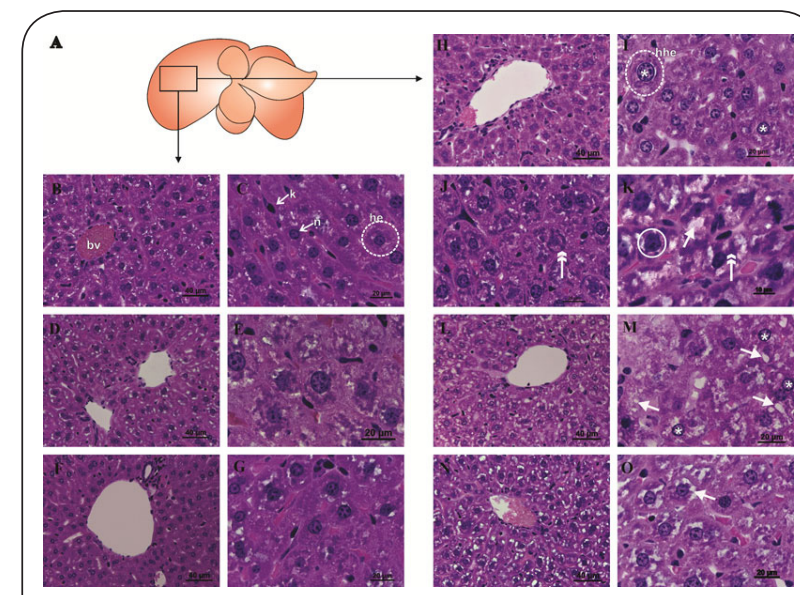

Figure 1. A: Picture of the anatomy of mouse liver; B-O: Histological sections of mice liver from the control and exposed groups, stained by Haematoxylin-Eosin. B and C: Control group I (exposed to distilled water); D and E: Control group II (exposed to $10 \%$ propylene glycol, fipronil diluent); F and G: Control group III (exposed to $30 \%$ ethanol, thymol solvent); H-K: Exposed group IV (exposed to $2 \%$ fipronil - synthetic chemical); L-O: Exposed group V (exposed to thymol $2 \mathrm{mg} / \mathrm{mL}$-natural chemical); he=hepatocyte; hhe=hypertrophic hepatocyte; $\mathrm{n}=$ hepatocyte nucleus; $\mathrm{CK}=$ Kupffer cell; Arrow=hepatocytes cytoplasmic vacuolation; Double arrow $=$ cytoplasmic granules in hepatocytes; Asterisk=hepatocyte nucleus with marginalized chromatin; Circle=irregularly shaped hepatocyte nucleus. Scale bar in each image.

changes were also observed, which included vacuolization between the hepatic cords, which caused a tissue disorganization. In the hepatocytes, the cytoplasm was also highly vacuolated (Figures $1 \mathrm{M}$ and 10 ) over the entire organ extension. There was also a change in the morphology and frequency of Kupffer cells (Figure 1M), which were quantified and verified the occurrence of hyperplasia (Figure 2).

\section{Thyroid}

Thyroid glands histological analysis of the control group I showed the presence of an intact tissue, where the thyroid follicles could be observed (Figure 3B), surrounded by a cubic and mononucleated follicular cells epithelium (Figure 3C). Inside the follicles, the colloids (prehormone) also showed an intact aspect (Figure 3B). In the extrafollicular region, the connective tissue filled the spaces and brought many blood vessels to the glandular tissue, responsible for collecting gland's secretion.

The glands from the control group II animals showed changes like the hypertrophy of some thyroid follicles (Figure 3D) when compared to control group I thyroids. It was also evident that the interfollicular region presented larger areas filled with connective tissue or adipose cells (Figure 3D). The follicular epithelium and the colloid were intact (Figure 3E).

In the control group III, the changes were similar to those from the control group II, that is, thyroid follicles hypertro-
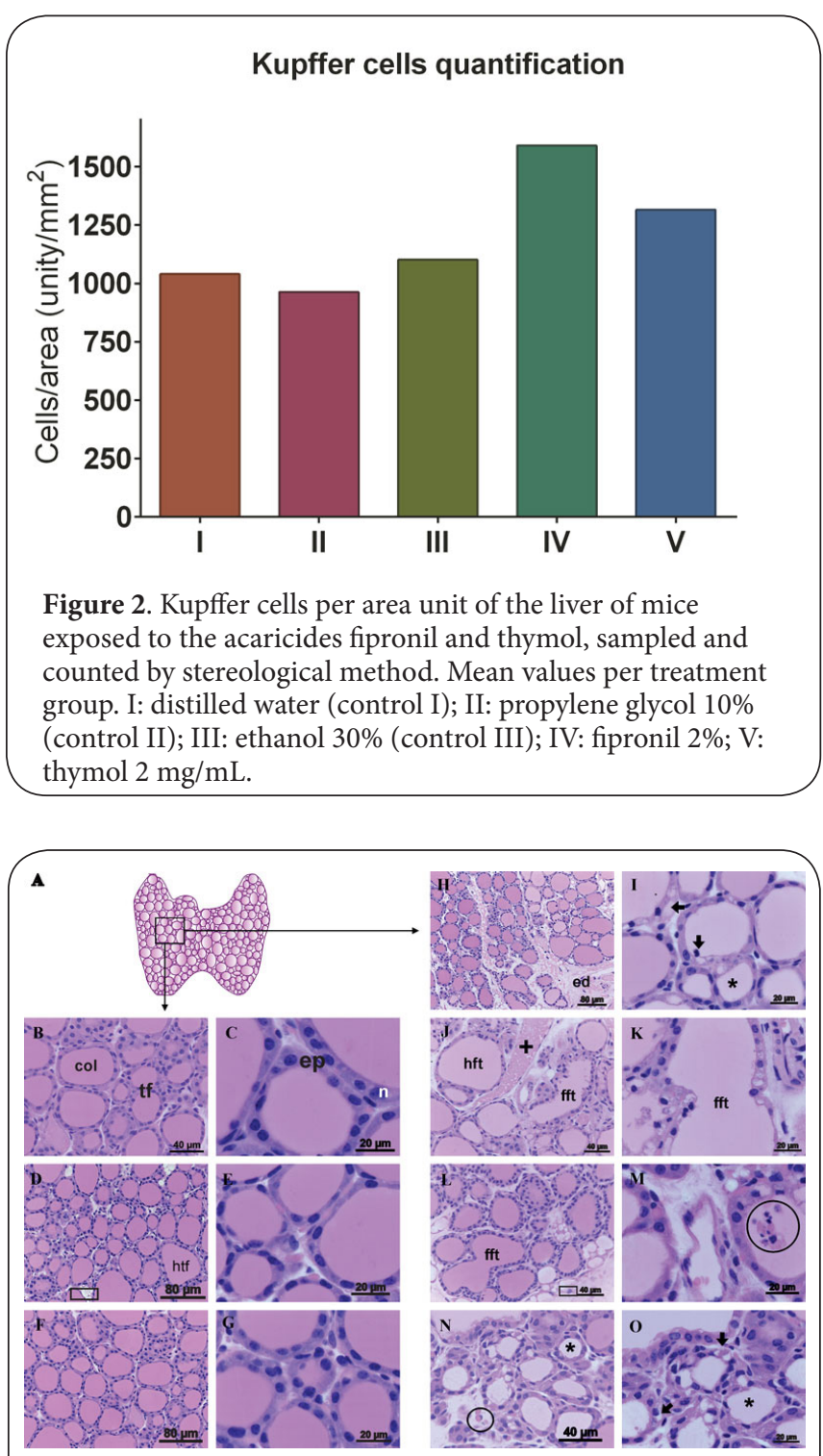

Figure 3: A: Thyroid scheme; B -O: Histological sections of mice thyroid from control and exposed groups, stained by Haematoxylin-Eosin; B and C: Control group I (exposed to distilled water); D and E: Control group II (exposed to 10\% propylene glycol, fipronil diluent); F and G: Control group III (exposed to 30\% ethanol, thymol solvent); $\mathbf{H}$ - K: Exposed group IV (exposed to $2 \%$ fipronil - synthetic chemical); L - O: Exposed group V (exposed to thymol $2 \mathrm{mg} / \mathrm{mL}$ natural chemical); ep = follicular epithelium; $\mathrm{n}=$ follicular cell nucleus; $\mathrm{tf}=$ thyroid follicle; $\mathrm{ft}=$ fused thyroid follicles; $\mathrm{htf}=$ hypertrophic thyroid follicle; $\mathrm{Col}=$ colloid; Asterisk = colloid weakly stained; ed = edema; Cross = increased caliber vessel; Circle = apoptotic body; Arrow = cytoplasmic vacuolization; Rectangle $=$ adipose cell. Scale bar in each image.

phy (Figure 3F). It was also observed follicular cell cytoplasm vacuolization. The colloid, as in the previous groups, was homogeneous (Figure 3G).

In the group IV (mice exposed to the synthetic acaricide, 
fipronil 2\%) it was observed more significant alterations provoked by the exposure to the chemical. Among them: 1) loss of the thyroid follicles original rounded form, since some of them acquired a totally irregular appearance (Figures $3 \mathrm{~J}$ and $3 \mathrm{~K})$; 2) loss of colloid integrity within the follicles, since they were stained with a greater or lesser intensity Figure 31);3) follicular cell vacuolation, which caused even the displacement of the nucleus from the central regions to the cell periphery (Figure 3I); 4) fusion of more than one follicle, causing a total structural disarrangement in the gland (Figures $\mathbf{3} \mathbf{J}$ and $\mathbf{3 K}$ ); 5) Increased interfollicular spaces and consequent occupation of the same by connective tissue, causing also regions with edema (Figure $\mathbf{3 H}$ ) and 6 ) increased vascularity of the gland, as well as increased caliber of blood vessels (Figure $3 \mathrm{~J}$ ).

The mice exposed to thymol, group V, showed thyroid with changes, which included the presence of follicles that lost their original rounded form, becoming irregular (Figure $3 \mathrm{~N}$ ). Thyroid follicles fusion (Figure $3 \mathrm{~L}$ ), although less frequent. The colloid within the follicles was also stained with a greater or lesser intensity, and some follicles were empty (Figures $\mathbf{3 N}$ and 30). Changes in follicular cells were like those observed in group IV. However, it was evident that some of the follicular cells underwent death processes, evidenced by the presence of structures like apoptotic bodies, within and outside the follicles (Figure $\mathbf{3 N}$ ). There was an increase in interfollicular spaces (Figure $\mathbf{3 L}$ ) and presence of fat cells in these spaces (Figure 3L).

Table 2 shows the alterations and their respective degrees of intensity were classified to better visualize the thyroid alterations of the mice from the different study groups.

Table 2. Intensity of histologic alterations in the thyroid of mice exposed to fipronil and thymol.

\begin{tabular}{llllll}
\hline Alteration & I & II & III & IV & V \\
\hline Edematous tissue & - & - & - & +++ & ++ \\
Fusion of more than one follicle & - & - & - & +++ & ++ \\
Follicle Hypertrophy & - & + & + & ++ & ++ \\
Colloid strongly positive & +++ & +++ & ++ & + & ++ \\
Colloid moderately positive & - & + & - & + & +++ \\
Colloid weakly positive & - & - & - & ++ & ++ \\
Vacuole in follicular cells & - & - & + & +++ & ++ \\
Apoptotic bodies' presence & - & - & - & + & +++ \\
Increased glandular vasculariza- & - & - & - & ++ & - \\
tion & & & & & \\
Fat cells' presence & - & + & - & ++ & ++ \\
\hline
\end{tabular}

Characterization with scores: No damage $(-)$, minor damage $(+)$, moderate damage $(++)$, severe damage $(+++)$. I (control distilled water), II (control propylene glycol 10\%), III (control ethanol 30\%), IV (fipronil treatment 2\%), V (treatment thymol $20 \mathrm{mg} / \mathrm{mL}$ ).

\section{Discussion}

Sustainability has been a great concern, not only for researchers, but also for governmental agencies that regulate the use of products to control pests (e.g., insects). Therefore, the search for efficient and sustainable alternatives is ongoing. The use of chemical products to control pests has been intensified, and the variety of chemicals used increase as the individuals to be controlled develop resistance mechanisms. Among these products are those with acaricide potential, used in the fields and homes, as the presence of domestic animals (e.g., dogs and cats) in the families has become increasingly common. The indiscriminate use of acaricides damages the environment and nontarget organisms, the latter including the hosts (in the case of ticks).

Fipronil is among the most widely used synthetic chemical acaricides; however, other products extracted from plants (e.g. thymol) have also been considered an alternative. Thus, the present study evaluated the histopathology of thyroid and liver, collected from mice exposed to the acaricides fipronil (synthetic) and thymol (natural), aiming to detect the alterations caused by the exposure of the animals (simulating a host).

The body mass alterations in the exposed mice were also evaluated, once such alterations are important indicators of the toxic effect of a certain substance in the animal organism. The results showed that the mice exposed to fipronil $2 \%$ gained less weight than those belonging to the other groups (including the one exposed to thymol). Similar results were obtained [28] conducting toxicity tests with exposure to cyanobacteria. According to the norms of Guideline 423 on acute toxicity [29], the reduction in the animal body mass is one of the systemic toxicity signals; and, in this study, fipronil $2 \%$ caused a decrease in the body weight values of the exposed animals.

\section{Liver}

The histological analysis showed that the hepatic tissue of the individuals belonging to the three control groups was intact, with preserved hepatocytes, arranged in cords and permeated by Kupffer cells, also intact $[21,24]$.

On the other hand, the individuals exposed to fipronil and thymol showed important histological alterations. Those exposed to fipronil at $2 \%$ displayed hepatocytes with highly basophilic cytoplasm, probably due to the presence of glycogen granules, corroborating the literature, which reports that the liver would be a multifunctional organ, storing reserve substances, in the case of animals, glycogen. This result suggests that the increase in synthesis of glycogen would be associated with more cytoplasmic granulation in the hepatocytes of these individuals [21]. Some studies reported that the variations in the glycogen delivery in the hepatocytes could indicate toxicity [30]. In addition, the cytoplasm of the hepatocytes showed regions with extended vacuolation, which, according to the literature, would indicate that the cell/tissue is developing strategies to remove the toxic product from the system by eliminating some cytoplasm regions and impaired organelles. These eliminated structures would be covered by membranes, forming autophagic vacuoles, that would 
be digested by lysosomes or released to the exterior. Similar results were found by authors who exposed other organisms to toxic products [31]. The nuclei of the hepatocytes showed chromatin marginalization and compaction, which could be associated with cell death processes due to the toxicity of the chemical products present in the system.

Another relatively frequent alteration observed was the hypertrophy of the hepatocyte, which could be directly associated with the metabolism increase and the protein synthesis in these cells, stimulated by the release of thyroid hormones, once a histopathologic alteration in the thyroid of the individuals exposed was also detected in this study. Hepatotoxicity studies in rats subjected to supraphysiological doses of thyroxine, reported hypertrophic hepatocytes resulting from the action of thyroid hormones [24].

The individuals exposed to both chemical products showed an increase in the number of Kupffer cells, macrophages that perform the phagocytosis of strange substances in the hepatic tissue, such as fat, drugs, among others. This increase in the number of macrophages would be directly associated with the strategy to remove the toxic product from the system to maintain the physiology integrity.

With specific regard to the individuals exposed to thymol, the hepatocytes showed vacuolation in the cytoplasm of the cells and among the hepatic cords, probably due to the intoxication by the acaricide.

Thus, the results of the histopathological analysis of the livers from the mice exposed to fipronil or thymol were similar, confirming that, regardless the origin (synthetic or natural), these substances are toxic to the mice, hosts, and nontarget organisms as well.

\section{Thyroid}

The thyroid is an important endocrine gland of the vertebrate, and has the function to regulate the metabolism by producing T3 and T4 hormones [32].

The histology of the thyroid tissue of the mice from the control groups did not show significant alterations. The tissue was intact, with preserved follicles, cuboidal and mononuclear follicle cells, forming an epithelium filled with colloid (prehormone). With specific regard to the group of mice exposed to propylene glycol $10 \%$ (fipronil diluent), the presence of hypertrophic follicles located in the central regions of the gland was observed, in addition to the adipose cells permeating the extrafollicular conjunctive tissue. The thyroids of the mice from control group III (ethanol 30\%, thymol diluent), in addition to follicle hypertrophy, displayed slight vacuolation in the cytoplasm of the follicular cells. These results confirm the thyroid sensitivity to alterations (even the slightest ones) in the organism of the animals, once in the bioassays using only propylene glycol $10 \%$ and the solvent ethanol $30 \%$ it was possible to observe alterations in this gland, confirming that the thyroid is an excellent toxicity indicator for vertebrate. Contrarily, the thyroid of the mice belonging to control group
I was intact, as described in the literature [21-23], which was expected, once only distilled water was used in the exposure.

In the individuals exposed to the chemicals (either synthetic or natural), the thyroid became disorganized after the treatment. The alterations suffered by the organ included: a) follicular disorganization; b) fusion of more than one follicle; c) edema in the interstitial tissue; d) increase in vascularization and in the gland blood vessel caliber; e) follicular cell vacuolation; f) alteration in the composition of the intrafollicular colloid and g) death processes occurring in the follicular cells. These alterations were probably caused by the presence of toxic substances in the system, modifying not only the morphology of this important organ, but also the physiology.

Studies developed by Ferreira M [33] corroborate our results, having demonstrated similar effects of different fipronil concentrations on the thyroid of nontarget organisms, including the fusion of two or more follicles, emergence of hypertrophic follicles, apoptotic bodies in the follicles (indicating cell death), enlargement of the spaces permeating the follicles and the presence of swollen regions. Leghait J [32] demonstrated that fipronil would chemically interact with the thyroid hormone production, causing morphophysiological alterations and overstimulating the gland. According to Hurley PM [34], who also studied the toxic potential of fipronil, a physiological imbalance between the thyroid and the hypophysis would occur, causing a decrease in hormones T3 and T4 circulation and an increase in the concentration of TSH (thyroid stimulating hormone). The consequences of such imbalance would be: 1) inhibition of inorganic iodate transportation to the interior of follicular cells; 2 ) lesions to the follicular cells; 3 ) inhibition of thyroid hormones release; 4 ) inhibition of colloid (prehormone) conversion into T3 and T4; 5) increase in the metabolic rate, and 6) increase in the liver hormone excretion.

These results clearly demonstrate that the synthetic acaricide fipronil is extremely aggressive, and can be considered a potent modifying agent of the morphophysiology of vertebrate organisms (including the tick hosts and nontarget organisms). However, evaluations of this type for natural acaricide products (e.g. thymol) are not available in the literature. Thus, the present study demonstrated that both acaricides, the synthetic (fipronil) and the natural (thymol, studied under this perspective for the first time) are potential stimulators of alterations in the thyroid tissue and, consequently, responsible for the alteration of the whole physiology of the individual.

Among the morphological alterations in the thyroid of the mice exposed to fipronil and thymol, the occurrence of death processes (apoptosis) was clear. In a natural context, the process of cell death is essential for the perfect development of vertebrate, allowing the elimination of useless cells or if there are any faults, mainly in the DNA. In the case of intoxication by synthetic or natural drugs, this process is directly associated with the exposure to the toxic products that pathologically induced the cell death. In addition to apoptosis, another alteration occurring in the thyroid tissue of the individuals 
Cunha et al. Journal of Histology \& Histopathology 2017,

exposed to the acaricides was the presence of edema, or accumulation of liquid in the interstitial space (extracellular), due to the impossibility of being removed by the lymphatic vessels (pathology or intoxication) [35].

\section{Conclusion}

Overall, the present study revealed that both thymol and fipronil can be considered potent modifiers of the morphology and, probably, of the physiology of the thyroid of the mice exposed, causing tissue disorganization and alterations in the colloid stored in the follicle.

The results confirm the need to minimize the short, medium and long-term damages caused by the application of acaricides, most times indiscriminate, affecting the natural hosts (directly) and nontarget organisms (indirectly).

Furthermore, the results demonstrated that the synthetic chemical acaricide fipronil was more aggressive to the hepatic and thyroid tissues of the mice exposed in comparison with the natural chemical thymol. The latter, however, caused important damages to the organs, which stimulates the search for new control strategies using chemical products that are efficient and, at the same time, sustainable for the environment and nontarget organisms, once the responsible governmental organs have not properly managed the use of acaricide products.

\section{Competing interests}

The authors declare that they have no competing interests.

\section{Authors' contributions}

\begin{tabular}{|l|c|c|c|c|c|c|}
\hline Authors' contributions & ELC & RSM & NRP & PRO & ED & MIC \\
\hline Research concept and design & $\checkmark$ & -- & -- & $\checkmark$ & $\checkmark$ & $\checkmark$ \\
\hline Collection and/or assembly of data & $\checkmark$ & $\checkmark$ & $\checkmark$ & $\checkmark$ & $\checkmark$ & -- \\
\hline Data analysis and interpretation & $\checkmark$ & $\checkmark$ & $\checkmark$ & $\checkmark$ & -- & $\checkmark$ \\
\hline Writing the article & $\checkmark$ & $\checkmark$ & -- & -- & -- & $\checkmark$ \\
\hline Critical revision of the article & -- & $\checkmark$ & -- & $\checkmark$ & -- & $\checkmark$ \\
\hline Final approval of article & $\checkmark$ & $\checkmark$ & $\checkmark$ & $\checkmark$ & $\checkmark$ & $\checkmark$ \\
\hline
\end{tabular}

\section{Acknowledgements}

The authors acknowledge the São Paulo Research Foundation (FAPESP), process 2014/13143-7, for financial support and the CNPq National Council of Scientific and Technologic Development for scholarships to the first author, PIBIC/CNPq, process 135958/2015-6.

\section{Publication history}

EIC: Gaetano Giuseppe Magro, University of Catania, Italy. Received: 27-Jun-2017 Final Revised: 25-Aug-2017 Accepted: 05-Sep-2017 Published: 17-Sep-2017

\section{References}

1. Dantas-Torres F. The brown dog tick, Rhipicephalus sanguineus (Latreille, 1806) (Acari: Ixoidae): From taxonomy to control. Vet. Parasitol. 2008; 152:173-185. | Article

2. da Rocha CM, Leite RC, Bruhn FR, Guimaraes AM and Furlong J. Perceptions of milk producers from Divinopolis, Minas Gerais, regarding
Rhipicephalus (Boophilus) microplus control. Rev Bras Parasitol Vet. 2011; 20:295-302. | Article | PubMed

3. Kunz SE and Kemp DH. Insecticides and acaricides: resistance and environmental impact. Rev Sci Tech. 1994; 13:1249-86. | PubMed

4. Nolan J. Mechanisms of resistance to chemicals in arthropod parasites of veterinary importance. Vet Parasitol. 1985; 18:155-66. | PubMed

5. Pruett JH. Immunological control of arthropod ectoparasites--a review Int J Parasitol. 1999; 29:25-32. | Article | PubMed

6. Rhône-poulenc. 'Fipronil' Worldwide Technical Bulletin. Rhône-Poulenc Agrochimie. 1995; 19.

7. Mencke $N$, Volf $P$, Volfova $V$ and Stanneck D. Repellent efficacy of a combination containing imidacloprid and permethrin against sand flies (Phlebotomus papatasi) in dogs. Parasitol Res. 2003; 90 Suppl 3:S10811. | Article | PubMed

8. Coop RL, Taylor MA, Jacobs DE and Jackson F. Ectoparasites: recent advances in control. Trends Parasitol. 2002; 18:55-6. | Article | PubMed

9. Wakita T, Yasui N, Yamada E and Kishi D. Development of a novel insecticide, dinotefuran. Journal of Pesticide Science. 2005; 30:122-123.

10. Pereira MC, Gasparotto AE, Jurgilas JP, da Silva LA, Silveira SS, Silva TN, Arnosti A and Camargo-Mathias MI. Detrimental effect of deltamethrin on the central nervous system (synganglion) of Rhipicephalus sanguineus ticks. Exp Appl Acarol. 2017; 71:159-169. | Article | PubMed

11. de Oliveira PR, Bechara GH, Denardi SE, Pizano MA and Mathias MI. Toxicity effect of the acaricide fipronil in semi-engorged females of the tick Rhipicephalus sanguineus (Latreille, 1806) (Acari: Ixodidae): preliminary determination of the minimum lethal concentration and LC(50). Exp Parasitol. 2011; 127:418-22. | Article | PubMed

12. Guelfi M, Maioli MA, Tavares MA and Mingatto FE. Citotoxicity of Fipronil on Hepatocytes Isolated from Rat and Effects of Its Biotransformation. Brazilian Archives of Biology and Technology. 2015; 58:843-853.

13. Regnault-Roger BJR. Philogène Past and current prospects for the use of botanicals and plant allelochemicals in integrated pest management. Pharm. Biol. 2008; 46:41-52.

14. Daemon E, Maturano R, Monteiro CM, Goldner MS and Massoni T. Acaricidal activity of hydroethanolic formulations of thymol against Rhipicephalus sanguineus (Acari: Ixodidae) and Dermacentor nitens (Acari: Ixodidae) larvae. Vet Parasitol. 2012; 186:542-5. | Article | PubMed

15. de Oliveira Souza Senra T, Zeringota V, de Oliveira Monteiro CM, Calmon F, Maturano R, Gomes GA, Faza A, de Carvalho MG and Daemon E. Assessment of the acaricidal activity of carvacrol, (E)-cinnamaldehyde, trans-anethole, and linalool on larvae of Rhipicephalus microplus and Dermacentor nitens (Acari: Ixodidae). Parasitol Res. 2013; 112:1461-6. | Article | PubMed

16. Broglio-Micheletti SM, Dias Nda S, Valente EC, de Souza LA, Lopes DO and Dos Santos JM. [Action of extract and oil neem in the control of Rhipicephalus (Boophilus) microplus (Canestrini, 1887) (Acari: Ixodidae) in laboratory]. Rev Bras Parasitol Vet. 2010; 19:44-8. | Article | PubMed

17. Vendramini MC, Camargo-Mathias MI, de Faria AU, Bechara GH, de Oliveira PR and Roma GC. Cytotoxic effects of andiroba oil (Carapa guianensis) in reproductive system of Rhipicephalus sanguineus (Latreille, 1806) (Acari: Ixodidae) semi-engorged females. Parasitol Res. 2012; 111:1885-94. | Article | PubMed

18. Sampieri BR, Furquim KC, Nunes PH and Camargo-Mathias MI. Rhipicephalus sanguineus (Acari: Ixodidae) female ticks exposed to castor oil (Ricinus communis): an ultrastructural overview. Parasitol Res. 2013; 112:611-9. | Article | PubMed

19. de Oliveira Monteiro CM, Daemon E, Silva AM, Maturano R and Amaral C Acaricide and ovicide activities of thymol on engorged females and eggs of Rhipicephalus (Boophilus) microplus (Acari: Ixodidae). Parasitol Res. 2010; 106:615-9. | Article | PubMed

20. da Silva Matos R, Daemon E, Camargo-Mathias MI, Furquim KC, Sampieri BR, Remedio RN, Araujo LX and Novato TP. Histopathological study of ovaries of Rhipicephalus sanguineus (Acari: Ixodidae) exposed to different thymol concentrations. Parasitol Res. 2014; 113:4555-65. | Article | PubMed 
Cunha et al. Journal of Histology \& Histopathology 2017,

http://www.hoajonline.com/journals/pdf/2055-091X-4-9.pdf

21. Junqueira LCU and Carneiro J. Histologia Básica. 12th ed. São Paulo: Editora Guanabara Koogan 2013.

22. NUNES MT. Hormônios tiroideanos: mecanismo de ação e importância biológica. Arq. Bras. Endocrinol. Metabol. 2003; 47:639-643.

23. Shi YB, Ritchie JW and Taylor PM. Complex regulation of thyroid hormone action: multiple opportunities for pharmacological intervention. Pharmacol Ther. 2002; 94:235-51. I Article I PubMed

24. Engelman MFB, Guidugli Neto J, Andrade CHV, Hernandez R and Goulart, LBNT. Estudo morfométrico do fígado de ratos submetidos a doses supra-fisiológicas de tiroxina. Arq. Bras. Endocrinol. Metabol. 2001; 45:173-179.

25. Rodrigues DS, Wanderley RPB and Leite RC. Aplicação de carrapaticidas em bovinos. In: C.J. Veríssimo, org. Resistência e controle do carrapatoboi. Arq. Instituto de Zootecnia. 2015; 1:29-56.

26. Russ JC and Dehoff RT. Practical Stereology 2nd ed. New York: Plemium Press. 2000

27. Amenábar JM, Padilha DMP, Hugo FN and Fossati ANM. Uso da estereologia como método na pesquisa histológica. Rev. Fac. Odontologia de Porto Alegre. 2003; 44:62-65.

28. Moreira ME and Barcinski MA. Apoptotic cell and phagocyte interplay: recognition and consequences in different cell systems. An Acad Bras Cienc. 2004; 76:93-115. | Article | PubMed

29. OECD. Guideline 423: Acute Oral Toxicity - Acute Toxic Class Method. Paris: Head of Publications Service. 2001.

30. Huggett, RJ. Biomarkers. Biochemical, Physiological, and Histological Markers of Anthropogenic Stress. Chelsea, MI: Lewis Publishers, 1992, 1-347.

31. Abreu MR, Rocha FA, Furquim KCS, Anholeto LA, Novaes FCF, Morsoleto MJ and Camargo-Mathias MI. Salivary Glands of Female Ticks Rhipicephalus sanguineus Like a Potential Source of Molecules with Inhibitory Action: In vivo study with Walker 256 Tumor Cells. Pharma Care Health Sys. 2014; 1:4.

32. Leghait J, Gayrard V, Picard-Hagen N, Camp M, Perdu E, Toutain PL and Viguie $\mathrm{C}$. Fipronil-induced disruption of thyroid function in rats is mediated by increased total and free thyroxine clearances concomitantly to increased activity of hepatic enzymes. Toxicology. 2009; 255:38-44. | Article | PubMed

33. Ferreira M, De Oliveira PR, Denardi SE, Bechara GH and Mathias MI. Fipronil (active ingredient of acaricide Frontline(R)) acting on the mice thyroid. Microsc Res Tech. 2012; 75:265-70. I Article I PubMed

34. Hurley PM. Mode of carcinogenic action of pesticides inducing thyroid follicular cell tumors in rodents. Environ Health Perspect. 1998; 106:43745. | PubMed Abstract | PubMed FullText

35. Ferreira E, Silva AE, Serakides R, Gomes AES and Cassali GD. Model of induction of thyroid dysfunctions in adult female mice. Arq. Bras. Medicina Veterinária e Zootecnia. 2007; 59:1245-1249.

\section{Citation:}

Cunha ELRd, Matos RdS, Pereira NRC, Oliveira PRd, Daemon E and Camargo-Mathias MI. Histopathological changes in the liver and thyroid of mice (Mus musculus) caused by the acaricides: fipronil and thymol. J Histol Histopathol. 2017; 4:9.

http://dx.doi.org/10.7243/2055-091X-4-9 